\title{
Comparing simulated glacial climate and paleodata:
}

\section{A reexamination}

\author{
A. J. Broccoli \\ Geophysical Fluid Dynamics Laboratory, NOAA, Princeton University, Princeton, New Jersey
}

E. P. Marciniak ${ }^{1}$

Atmospheric and Oceanic Sciences Program, Princeton University, Princeton, New Jersey

\begin{abstract}
Glacial sea surface temperatures (SSTs) simulated by an atmosphere-mixed layer ocean model are compared with those reconstructed by the Climate: Long-Range Investigation, Mapping, and Prediction (CLIMAP) Project using planktonic microfossils. Two methods of comparison are employed. The first is global and uses the subjectively analyzed (i.e., hand contoured, then digitized) data set published by CLIMAP. The second is restricted to only those discrete locations where the CLIMAP sediment cores were taken. Both methods indicate that many aspects of the reconstructed glacial SST changes are simulated reasonably well by the model, although there are areas of disagreement. The extent of the disagreement appears smaller when the SSTs are sampled at discrete locations, because the largest discrepancies occur in the subtropical Pacific where data are sparse. When examined separately for each ocean, the magnitude of the disagreement in low latitudes roughly corresponds to the magnitude of the uncertainties in SST estimation using planktonic microfossils, being largest in the Pacific and smallest in the Atlantic. Because the largest discrepancies occur where uncertainties in estimation are large, no clear determination of whether the climate model exaggerates or underestimates low-latitude climate sensitivity appears possible.

Nonetheless, sampling at discrete locations may be the best procedure for evaluating climate model performance, because errors associated with extending analyses to data-void areas can be avoided and uncertainties associated with inadequate spatial sampling made more evident.
\end{abstract}

\section{Introduction}

The possibility of substantial changes in climate as a result of human activities has heightened interest in past climates because of their potential for improving our understanding of climate processes. Because anthropogenic greenhouse gases and aerosols are modifying the radiative properties of the atmosphere, a subject of particular interest is how the global distribution of temperature changes in response to changes in radiative forcing. Three-dimensional global climate models provide estimates of this response, often called the climate sensitivity, based on numerical modeling. Paleoclimatic data have the potential to allow the climate sensitivity to be evaluated based on the observed climate record by providing estimates of past radiative forcing and temperature change.

One way to exploit the potential of paleoclimatic data for this purpose is to devise climate modeling experiments in

\footnotetext{
${ }^{1}$ Now at Lincoln Laboratory, Massachusetts Institute of Technology, Lexington.

Copyright 1996 by the American Geophysical Union.

Paper number 95PA03311.

0883-8305/96/95PA-03311\$10.00
}

which the changes in radiative forcing are prescribed based on the geological record. The changes in temperature simulated by the model can then be compared with paleotemperature reconstructions. In experiments designed for this purpose, it is important for the model to predict sea surface temperature (SST) as well as land temperature, because prescribing SST, as has been done in many paleoclimate simulation experiments, will strongly constrain the thermal response of the model. A straightforward way of predicting SST is to couple an atmospheric general circulation model to a simple model of the ocean mixed layer. This approach was employed by Manabe and Broccoli [1985a], who used changes in continental ice, atmospheric composition, landsea distribution, and surface albedo to examine the ability of their climate model to simulate the climate of the last glacial maximum (LGM). Comparing paleoclimatic estimates of SST and surface air temperature to those simulated by their climate model, they found an encouraging amount of agreement despite some significant differences.

This paper adopts the premise that such comparisons of paleoclimate simulations with reconstructed climate are useful in assessing climate model performance because they allow models to be tested under conditions very different from the present. While the greater uncertainty of paleoclimate estimates (relative to instrumental records) is an 
Table 1. Boundary Conditions Used for Climate Model Simulations

\begin{tabular}{lcc}
\hline & Modern & Last Glacial Maximum \\
\hline Land-sea distribution & modern & sea level lowered by 150 m \\
Continental ice distribution & modern & $\begin{array}{c}\text { CLIMAP Project Members [1981], } \\
\text { maximum reconstruction }\end{array}$ \\
Snow-free land albedo distribution & modern & CLIMAP Project Members [1981] \\
Atmospheric $\mathrm{CO}_{2}$ concentration & $300 \mathrm{ppm}$ & $200 \mathrm{ppm}$ \\
\hline
\end{tabular}

important complication, the ongoing development of climate models and improvement of paleoclimatic databases make it desirable to conduct such assessments periodically. In the subsequent sections, the LGM climate simulation of Manabe and Broccoli [1985a] is used in conjunction with the SST reconstruction prepared by the Climate: LongRange Investigation, Mapping, and Prediction (CLIMAP) Project [CLIMAP Project Members, 1981] to explore some of the issues involving the interpretation of previous such comparisons, their optimal design, and their implications for the future expansion of the paleoclimatic database.

\section{Description of Climate Model}

The climate model output used in this study is taken from the present-day and LGM climate simulations performed by Manabe and Broccoli [1985a] with a coupled atmosphere-mixed layer ocean model. The version of the model with prescribed cloud cover is used because it has been analyzed extensively [Broccoli and Manabe, 1987], and therefore its output remains readily available. SST and sea ice are predicted quantities in this model, based on the boundary condition that the surface heat balance must be satisfied. This means that the simulated SST and sea ice distributions are independent of paleoclimatic reconstructions of ocean surface conditions and thus can be meaningfully compared with such reconstructions. For the LGM simulation, the continental ice extent, land-sea distribution, land surface albedo, and atmospheric composition were altered from their present-day values as indicated in Table 1. After a spin-up period was completed and the simulated climate had reached a quasi-equilibrium state, the output from the modern and LGM integrations was averaged over 10 and five annual cycles, respectively. SST differences were then computed from these time averages.

The atmosphere-mixed layer ocean model accounts for the thermal inertia of the upper ocean, which is essential for simulating the seasonal variation of climate. However, other aspects of the ocean's role in climate are not represented. Because the simple mixed layer is static, there are no ocean currents. Accordingly, there is no horizontal heat transport by the ocean. Also, no heat exchange can occur between the mixed layer and the deeper ocean, and the depth of the mixed layer is assumed to be globally uniform and constant. These limitations should be considered when interpreting the model results, because some of the responses of a more complete coupled model (e.g., changes in upwelling, oceanic fronts, and advective plumes) will be absent. In addition, the atmospheric component of the model is simplified by prescribing cloud cover and thereby neglecting cloud feedback, which has been shown to play an important role in the magnitude of climate model sensitivity [Cess et al., 1989]. In the comparison of Manabe and Broccoli [1985a], neglecting cloud feedback was found to produce an approximately $17 \%$ reduction in the sensitivity of global mean SST. (For a more complete description of the climate model, see Manabe and Broccoli [1985a] and Broccoli and Manabe [1987].)

\section{Marine Paleotemperature Data}

The marine paleotemperatures for the LGM that form the basis for evaluating the climate model are taken from the CLIMAP Project Members [1981] SST reconstiuction, as available from the National Geophysical Data Center. In this data set, SSTs were reconstructed by determining the present-day relationships between various marine microorganisms and the temperature of the ocean waters that they inhabit and applying those relationships to past periods by examining the shells deposited in deep-sea sediments. While revisions to the CLIMAP reconstruction have been suggested during the time since its compilation [e.g., Anderson et al., 1989], this study uses the data set in its original form because, at present, it constitutes the only global SST database for the last glacial and has been widely used in climate modeling experiments.

When using the CLIMAP data for climate model evaluation, the procedure by which they were produced should be clearly understood. Unfortunately, the easy availability of global SST maps or gridded data can obscure the details of this process. Employing a methodology pioneered by Imbrie and Kipp [1971], CLIMAP related microfossil abundances in modern sediments (i.e., core tops) to presentday SSTs using a combination of statistical techniques. This allowed the development of transfer functions that yield an estimate of SST when the faunal or floral distribution for a 


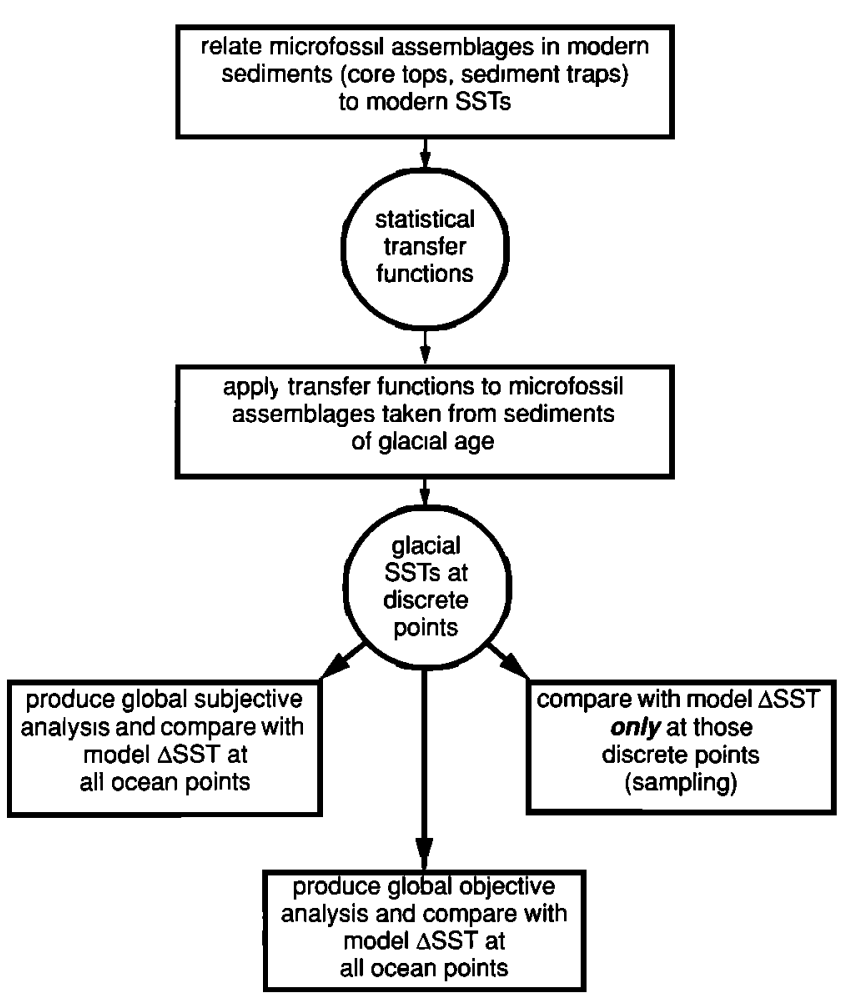

Figure 1. Flow diagram illustrating three methodologies for comparing climate model simulations to paleoclimatic data. SST is sea surface temperature.

given place and time is provided. These transfer functions were then applied to planktonic abundances taken from sediments of glacial age to produce estimates of LGM SST at the discrete locations where appropriate sediments were available. Because these locations are not uniformly distributed in space and CLIMAP's goal was to produce global maps of SST, a subjective analysis procedure (i.e., contouring by hand) was used. The resulting global contour maps were then digitized on a regular grid, the form in which the CLIMAP reconstructions have been most widely used in climate modeling.

In previous evaluations of LGM climate simulations using CLIMAP data [Manabe and Broccoli, 1985a, b; Broccoli and Manabe, 1987], the subjectively analyzed, glacial SST anomalies on a global ocean grid were compared with the corresponding simulated SST changes. This procedure is represented as the left branch of the flowchart depicted in Figure 1. Two other approaches to performing the comparison can also be identified. The first, illustrated in the center branch of the flowchart, is very similar to the procedure described above, except that an objective analysis technique [e.g., Levitus, 1982] is employed to produce SST values at each point on a regular grid from a nonuniform distribution of discrete data points. In the second approach, the comparison of simulated and reconstructed SST changes is made only at those locations where the original discrete data are available. This is illustrated in the right branch of the flowchart.

Each of these methods has distinct advantages and disadvantages. Both global analysis methods, subjective and objective, can provide estimates of SST change at all locations, although the basis for doing so may be somewhat arbitrary. With subjective analysis, the analyst can draw on physical insights to estimate SST patterns in data-void areas. This can produce results that are more physically appealing, but it also introduces the risk of a potential bias based on the assumptions of the analyst. Objective analysis uses a specific algorithm and thus provides a reproducibility not offered by subjective methods, but the choice of an algorithm is still arbitrary. Objective analysis also allows the quantitative determination of the sensitivity of the analysis to a specific data point (or set of points). In contrast to these two methods, comparisons made by sampling at discrete locations are free of errors that may be introduced by the process of extending the analysis to data-void or datasparse regions. However, this method also has the drawback of emphasizing some areas and ignoring others when the distribution of data is very nonuniform.

In the next two sections, comparisons between simulated and reconstructed SST changes will be made based on two of these three methods: by using the CLIMAP global subjective analysis and by sampling at the discrete locations where the underlying data were taken. With this parallel set of comparisons, the possibility that previous conclusions about model-paleodata agreement are sensitive to the method of comparison can be explored. The results may also be relevant in identifying geographical areas where the assessment of climate model performance is difficult because of inadequacies or inconsistencies in LGM climate reconstruction.

\section{Comparison With CLIMAP Subjective Analysis}

For this comparison, the gridded SSTs taken from the CLIMAP database are used directly. CLIMAP determined the present-day temperatures from United States Naval Hydrographic Office climatological atlases and the LGM temperatures from subjective analyses constructed according to the procedure described in the previous section. Both were digitized on a $2^{\circ}$ by $2^{\circ}$ grid for the months of February and August. Using these four data sets, the CLIMAP glacial SST anomalies are computed by averaging the February and August values and subtracting the present-day SST from the LGM SSTs. These are compared with the corresponding SST differences simulated by the climate model.

An examination of maps of these two data sets (Plate 1) reveals notable similarities and differences between the simulated and CLIMAP SST anomalies. Among the similarities is the location of the largest negative values in the subpolar North Atlantic, where the reconstructed glacial 


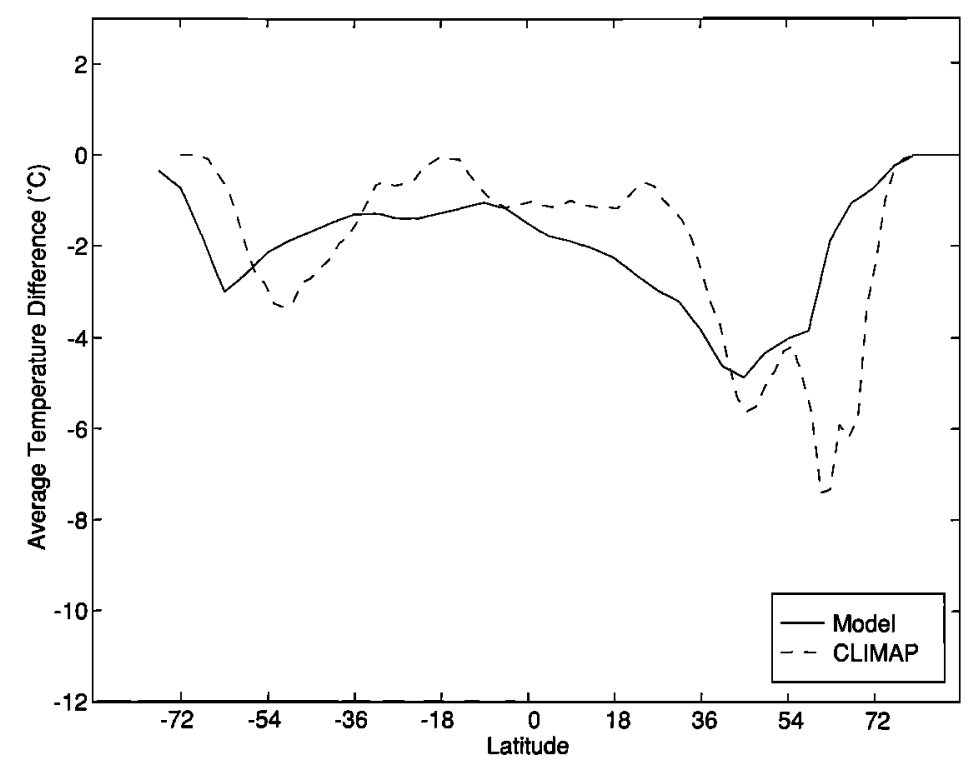

Figure 2. Differences in average of February and August zonal mean sea surface temperature (degrees Celsius) between last glacial maximum and present: solid line, simulated by climate model, using all model grid boxes; dashed line, reconstructed by CLIMAP, using gridded subjective analysis.

cooling exceeds $10^{\circ} \mathrm{C}$. Both the simulated and reconstructed SSTs also indicate a band of enhanced cooling in the Southern Ocean, although the simulated version of this feature is located somewhat poleward of its CLIMAP counterpart. The contrast between the very large cooling of the entire North Atlantic and the more modest cooling of the North Pacific is also present in both the model and CLIMAP anomalies. The most prominent discrepancy occurs in the subtropical gyres of the North and South Pacific, where the CLIMAP reconstruction indicates a modest warming during glacial times, whereas the model simulates a modest cooling. Elsewhere, areas of enhanced cooling over the extreme western North Pacific and the eastern subtropical North Atlantic are not evident in the model's temperature anomalies, probably because they resulted from changes in ocean circulation that cannot be simulated by the static mixed layer ocean component of the climate model. The area of large CLIMAP-model disagreement over the Coral Sea is not of consequence, because revised glacial SST estimates for this region eliminate the large positive anomalies present in the original reconstruction [Anderson et al., 1989].

Latitudinal trends in the model and CLIMAP glacial temperature anomalies can be compared by examining their zonal averages (Figure 2). The use of zonal averages emphasizes larger-scale thermal patterns and de-emphasizes features associated with smaller-scale variations, such as small changes in the location or intensity of ocean currents. Both the model and CLIMAP anomalies show similar broad patterns, with the largest cooling centered in the middle and subpolar latitudes of the northern hemisphere, a second, less intense area of cooling in the southern subpolar region, and a relatively small cooling in low latitudes. The magnitude of the simulated anomalies in each of these extratropical cooling maxima is quite similar to the CLIMAP reconstruction. Virtually no SST change occurs at the highest latitudes because the presence of sea ice for both present-day and glacial times maintains underlying water temperatures at the freezing point.

Notable differences are again evident in the zonal means as they were in the anomaly maps. Both simulated extratropical cooling maxima are shifted southward of their CLIMAP counterparts. Sea ice may play a role in both of these discrepancies, since Manabe and Broccoli [1985b] documented the close relationship between sea ice extent and the location of maximum SST cooling in their study of the effects of continental ice sheets on ice age climate. Their result suggests that accurate simulation of the sea ice extent in the present-day climate simulation may be a necessary condition for realistic placement of these maxima. Because the simplified ocean treatment in the climate model precludes horizontal heat transport by the ocean and no heat flux adjustment was used to mimic this process, the boreal sea ice margin in the present-day simulation is located too far south. This should, in turn, have shifted the location of the largest simulated SST cooling farther south. In the southern hemisphere, the simulated sea ice margin is considerably more realistic, but the possibility that CLIMAP overestimated the sea ice extent at the LGM [Burckle et al., 1982] could mean that their SST cooling maximum is too far north in the high-latitude South Pacific. The combination of improved simulation of the present-day sea ice mar- 
gin (e.g., through the use of a heat flux adjustment) and a revision of the original LGM sea ice reconstruction toward smaller extent might reduce the model-CLIMAP disagreement in these areas. Changes in ocean circulation features, such as the subtropical convergence in the Southern Ocean, make a more important contribution to the model-CLIMAP differences in the vicinity of the southern hemisphere extratropical cooling maxima, and these are unrepresented due to the absence of ocean dynamics in the current model.

The other major discrepancy occurs in low latitudes, where the CLIMAP zonal mean cooling is $1^{\circ} \mathrm{C}$ or less as opposed to $1^{\circ} \mathrm{C}-2.5^{\circ} \mathrm{C}$ in the model. The source of much of this disagreement is the warmth of the LGM subtropical gyres (particularly in the Pacific) in the CLIMAP reconstruction which is not simulated by the model. It has been suggested that this warmth is a dynamical response of the ocean to changes in atmospheric circulation [Moore et al., 1980], in which case the simplified treatment of the model ocean would preclude its simulation. The dissimilarity between the simulated and CLIMAP temperature anomalies in these regions is an important issue that will be explored in greater detail in subsequent sections.

\section{Comparison With CLIMAP by Sampling at Discrete Points}

In this section, the simulated and CLIMAP glacial SST anomalies are compared only at those locations where the sediment cores that form the basis of the global SST reconstruction were taken. Using sediment core locations taken from Table 3 of CLIMAP Project Members [1981], glacial SST anomalies were computed based on the interpolated glacial and present-day temperatures from the gridded SST reconstructions described in the previous section. This procedure results in an estimate of the annual mean SST change at each core location.

To facilitate the comparison with the model, the world is divided into boxes corresponding to the climate model's $4.5^{\circ}$ latitude by $7.5^{\circ}$ longitude grid. For each of these boxes, an LGM temperature anomaly is computed only if there is a CLIMAP core located within its boundaries. If more than one core falls within the box, the values are averaged to form the anomaly. These anomalies are compared with those simulated by climate model (for the same grid boxes) in Plate 2.

Because the identical underlying information (i.e., the model output and the gridded CLIMAP data set) was used in producing Plate 2 , the same patterns are present as appear in Plate 1. In this case, however, the nonuniform availability of glacial SST estimates is immediately evident. Both biological and geochemical considerations influence their distribution. As discussed by Ruddiman [1985] the best areas for climate reconstructions are those with relatively high sedimentation rates, a diverse, well-preserved microfossil record, and the absence of major physical or chemical alteration of the original information. These tend to be located relatively close to the equator, in middle to high latitudes, and along coastal margins. Poorer areas for climate reconstruction are the subtropical gyres, where productivity is low, and deep ocean basins, where corrosive bottom waters are found.

The spatial distribution of the CLIMAP SST reconstructions is consistent with these considerations. The Atlantic is sampled best, since it is both shallower and has less corrosive deep water. At the other extreme the Pacific is rather poorly sampled, particularly in the subtropical gyres. The quality of data coverage for the Indian Ocean is poorer than that of the Atlantic but better than in the Pacific. Because there are physical reasons for these differences in spatial sampling, zonal mean temperature anomalies are computed from the CLIMAP reconstructions and climate model simulation for each of these oceans (Figure 3) using only those grid boxes with CLIMAP cores. The size of the solid circle representing the CLIMAP value is proportional to the fraction of the grid boxes for that latitude and ocean at which data are available.

The agreement between the model and CLIMAP is excellent through most of the Atlantic (Figure 3a), with the differences in zonal mean temperature anomalies generally less than a degree. Two exceptions are in the high latitudes of both hemispheres, where errors in sea ice simulation and an inability to simulate changes in the location of the subtropical convergence may contribute to larger discrepancies, as discussed in the previous section. In the Indian Ocean (Figure $3 b$ ) agreement is generally good at low latitudes, with larger disagreement in middle and high latitudes, where the CLIMAP cooling is larger than that simulated by the model. Because the reconstructed glacial cooling in this region has been interpreted as indicating a shift in the oceanic subtropical convergence, a more complete treatment of the ocean would be required to simulate it. The model-CLIMAP agreement in the Pacific is more difficult to assess due to the poor spatial sampling. Data are fairly plentiful in the high-latitude North Pacific, where the agreement is good. At other latitudes the agreement is fair except in the subtropics of both hemispheres, where the model simulates a modest cooling while CLIMAP indicates a modest warming. While these are poorly sampled areas, the disagreement there is intriguing because it involves the sign of the temperature change and because the CLIMAP anomalies are rather consistent at the relatively few points where they are available.

A global plot of zonal mean SST anomalies (Figure 4) is useful for summarizing the comparison between the model simulation and the CLIMAP reconstruction. This plot closely resembles the plot for the Atlantic (Figure 3a), in part because the latitudinal structure is somewhat similar in each ocean (cooling maxima in high latitudes of both hemispheres, with the larger cooling in the northern hemisphere), but also because the better spatial sampling in the 

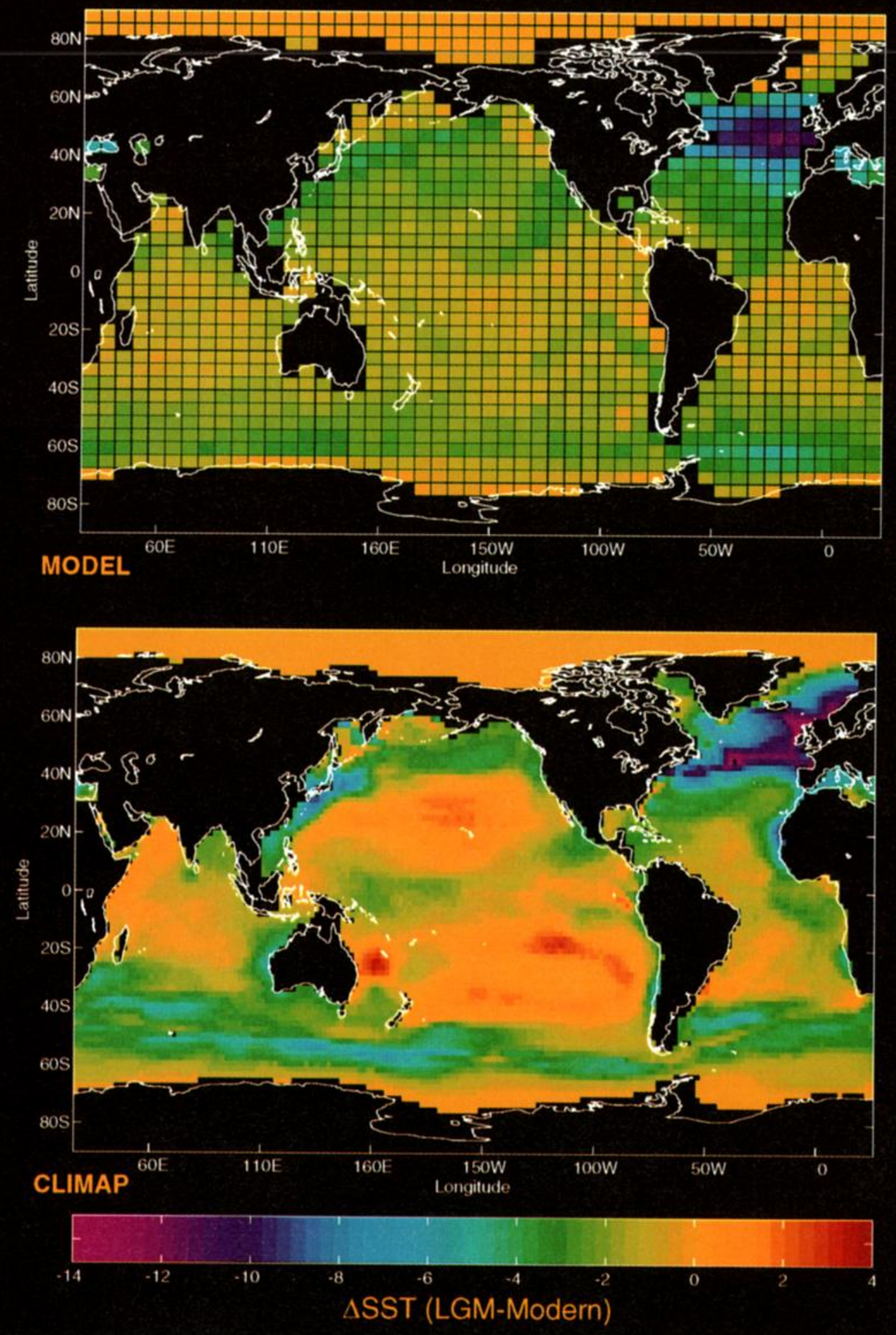

Plate 1. Differences in average of February and August sea surface temperature (SST) (degrees Celsius) between last glacial maximum (LGM) and present: (a) simulated by climate model, using all model grid boxes; (b) reconstructed by Climate: Long-Range Investigation, Mapping, and Prediction (CLIMAP), using gridded subjective analysis. 

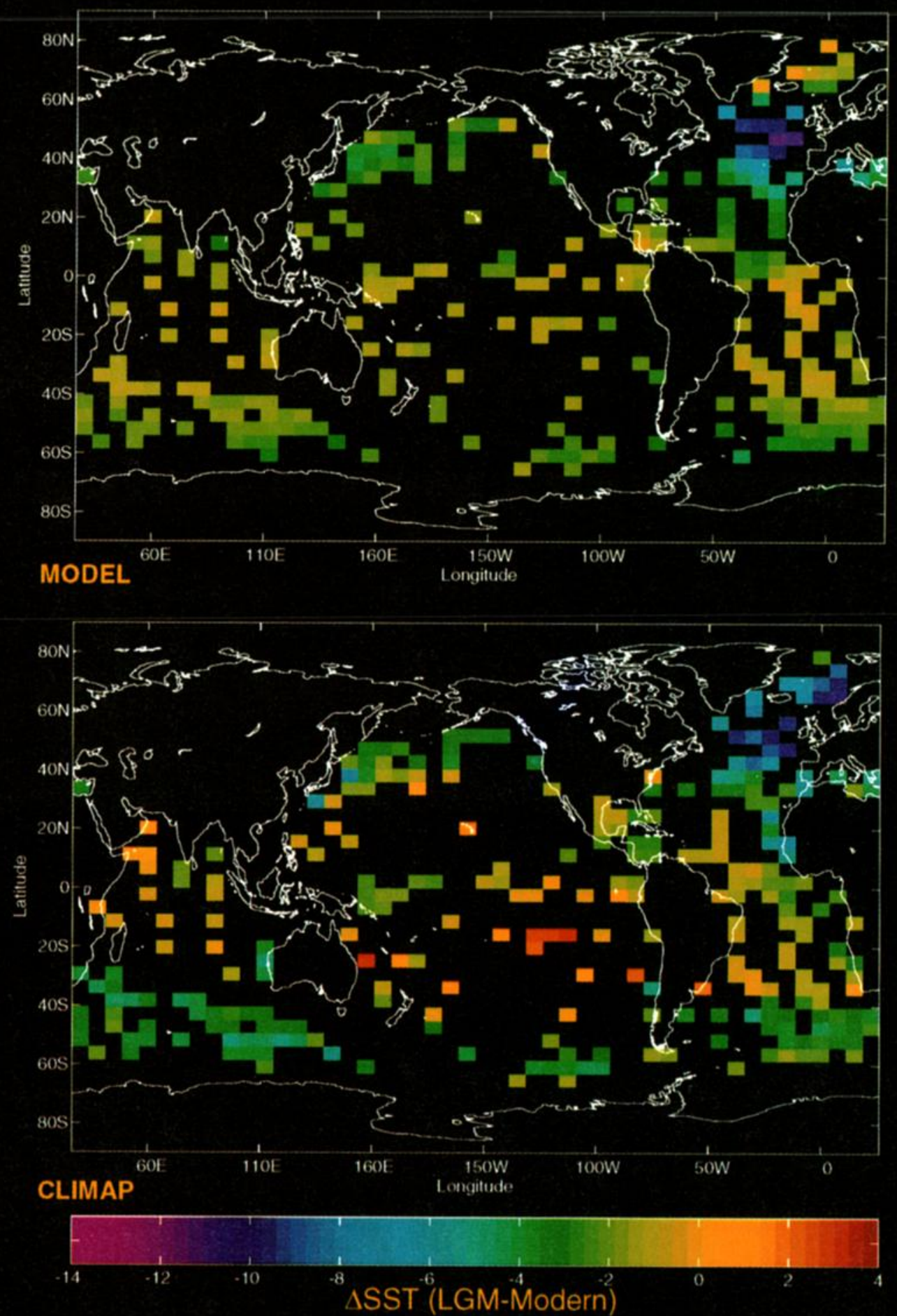

Plate 2. Differences in average of February and August sea surface temperature (degrees Celsius) between last glacial maximum and present at only those model grid boxes where CLIMAP cores are located: (a) simulated by climate model; (b) reconstructed by CLIMAP. 

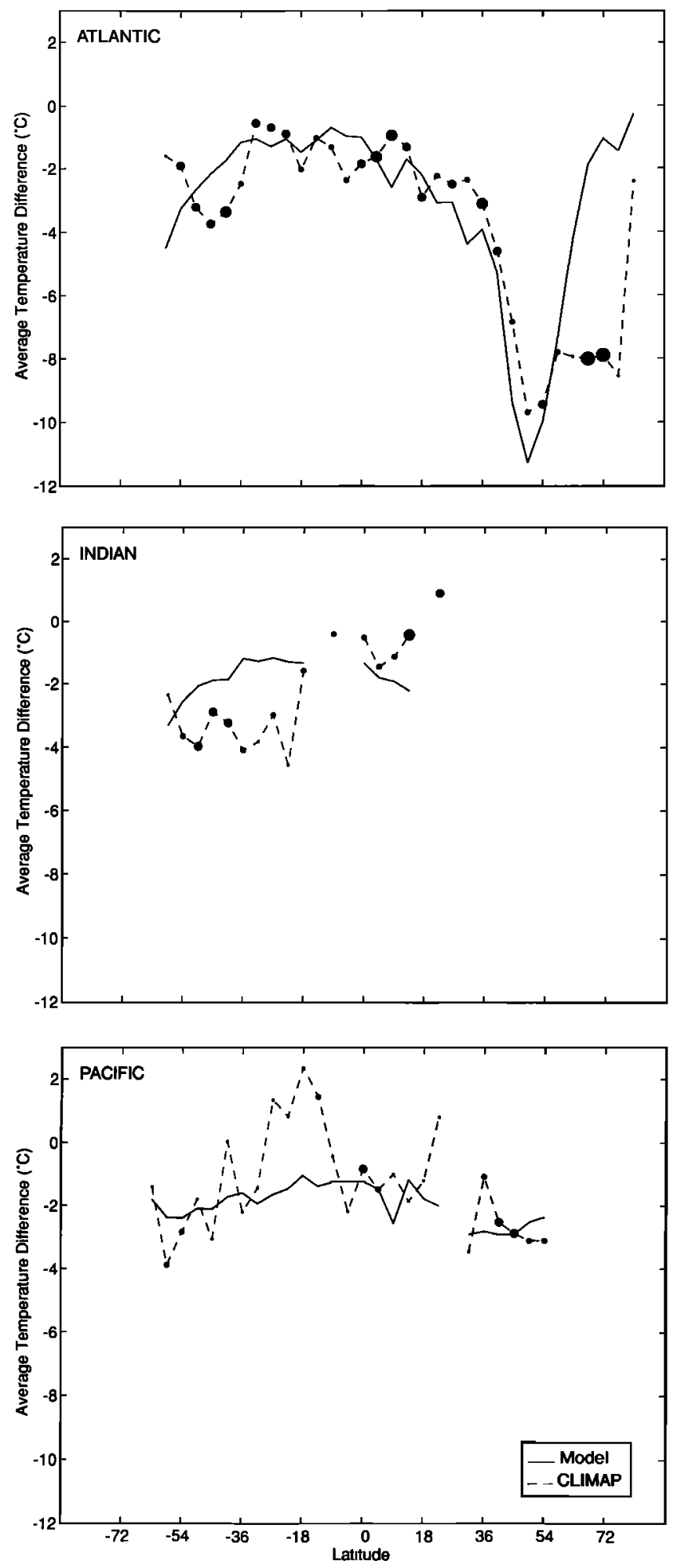

Figure 3. Differences in average of February and August zonal mean sea surface temperature (degrees Celsius) between last glacial maximum and present using only those model grid boxes where CLIMAP cores are located (solid line, simulated by climate model; dashed line, reconstructed by CLIMAP) for (a) Atlantic Ocean, (b) Indian Ocean, and (c) Pacific Ocean.
Atlantic allows it to contribute a larger number of grid points to the zonal average. Thus the largest discrepancies are in the northern high latitudes (where almost all data are from the North Atlantic) and the middle to subpolar southern latitudes. As noted earlier, errors in the modern sea ice simulation, the simple ocean model's inability to simulate shifts in ocean currents, and questions about the austral summer sea ice reconstruction for the LGM are likely contributors to these discrepancies.

In contrast to the zonal averages computed from the CLIMAP subjective analysis (Figure 2), the CLIMAP-model disagreement in the subtropics does not appear very dramatic in this plot. This is a consequence of the small number of locations where paleotemperature estimates exist that support the positive glacial SST anomalies reconstructed by CLIMAP but not simulated by the model. Thus the perception of better agreement in Figure 4 may be cosmetic if the temperature estimates at those locations are both accurate and representative of the subtropical gyres as a whole. Another interpretation, however, is that the CLIMAP temperature changes in these areas are not constrained by data nearly as well as they are elsewhere.

\section{Summary and Discussion}

This study utilizes two methods for comparing glacial SST anomalies simulated by a climate model to the SST estimates produced by the CLIMAP project. In the first method, the CLIMAP paleotemperatures estimated at discrete locations (i.e., where sediment cores were taken) are subjectively analyzed to produce a global, gridded data set. These data are then subtracted from a modern SST analysis to produce glacial SST anomalies, which are compared with the simulated anomalies. This method has been used in a number of previous studies [Manabe and Broccoli, 1985a, b; Broccoli and Manabe, 1987]. A second method is introduced in which the simulated and observed SST anomalies are compared only at the discrete locations where the original paleotemperature estimates were made. This obviates the need for arbitrarily estimating temperature patterns in data-void regions.

\subsection{Comparison Between Climate Model and CLIMAP Temperatures}

Both of the above methods indicate that the model has successes and failures in simulating the large-scale patterns of SST change reconstructed by CLIMAP. The successes include the simulation of the largest glacial cooling in the subpolar North Atlantic, a secondary maximum of cooling in the Southern Ocean, and the contrast between the large overall cooling of the North Atlantic and the more modest cooling of the North Pacific. The model fails to show enough cooling in the high-latitude North Atlantic and also locates the Southern Ocean cooling too far south. The absence of horizontal heat transport by the simple mixed 


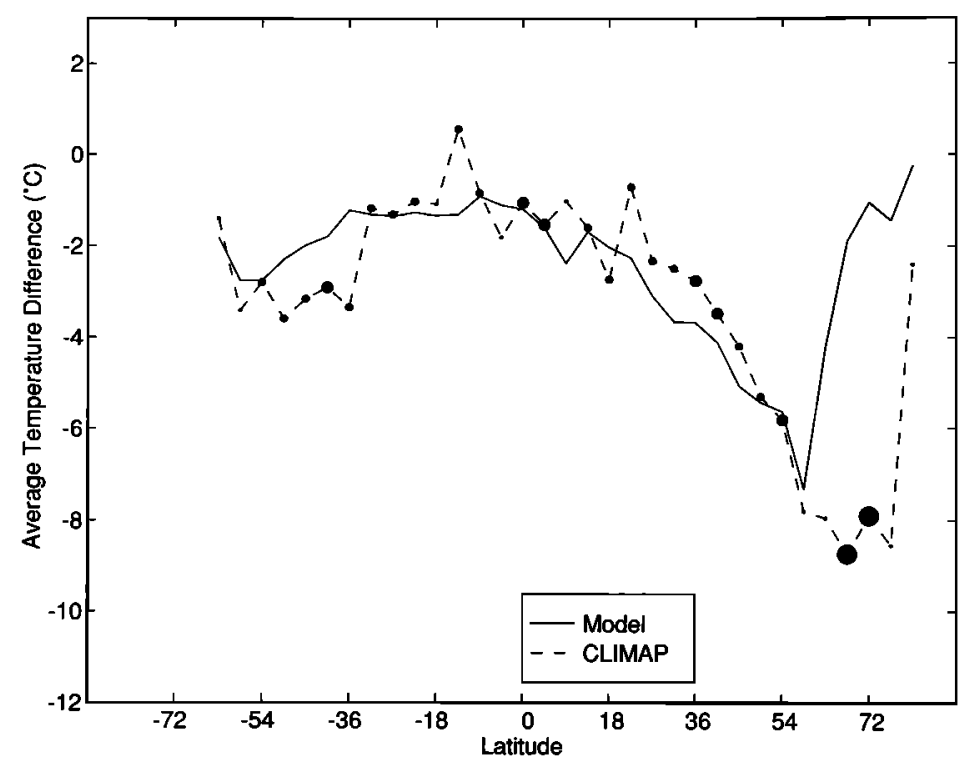

Figure 4. Same as Figure 3, except for all oceans combined.

layer ocean and the lack of heat flux adjustment to mimic its effects contribute to the first of these model-CLIMAP disagreements. The latter disagreement is probably due to the inability of the simple mixed layer ocean model to simulate shifts in the subtropical convergence zone, although uncertainties in the CLIMAP sea ice reconstruction in the southern hemisphere [Burckle et al., 1982] may also have some effect on the reconstructed glacial SST anomalies at high latitudes. The failure to simulate regions of enhanced cooling (suggestive of enhanced upwelling) off the west coasts of northern Africa and Australia is probably due to the absence of ocean dynamics.

A case of model-CLIMAP disagreement that is very prominent in the subjective analysis but not so evident when sampling at discrete points concerns the simulation of low-latitude temperatures, particularly in the Pacific. Based on a relatively sparse set of SST estimates, the CLIMAP subjective analysis indicates vast regions in the subtropical gyres where glacial temperatures were either very similar or warmer than present. These regions strongly influence the zonally averaged SST anomalies depicted in Figure 2, leading to a large mismatch between the model simulation and the CLIMAP estimates. When sampled at discrete points, the paucity of data from these regions decreases their influence on the zonal averages (Figure 4), allowing for a closer agreement between the model output and the paleotemperature estimates.

\subsection{Low-Latitude Temperatures}

The dependence of the apparent magnitude of the modelCLIMAP disagreement at low latitudes on the method of comparison indicates that the uneven spatial distribution of the SST estimates is a significant complication in evaluat- ing model performance. Because many of the biological and geochemical factors that lead to sparse data coverage can also make SST estimation using planktonic microfossils difficult, the complication may extend beyond the issue of how to fill the gaps in data coverage. Questions have long been raised about the validity of the CLIMAP low-latitude SST reconstruction [Webster and Streten, 1978; Rind and Peteet, 1985]. Most of those questions were motivated by comparing the CLIMAP estimates with evidence for substantially larger glacial cooling based on paleoclimatic indicators (e.g., snow lines, pollen) from tropical mountains. Because of the differences in elevation, changes in the atmospheric lapse rate have been invoked as a way to reconcile these two lines of evidence [Broecker and Denton, 1989; Sun and Lindzen, 1993], although the results from the climate model indicate that tropical lapse rates remain close to the moist adiabatic in both the modern and LGM simulations.

More recent work provides additional paleotemperature evidence from locations at or near sea level based on other indicators. Isotopic data from corals off Barbados indicate glacial SSTs $5^{\circ} \mathrm{C}$ colder than today [Guilderson et al., 1994], and a shorter record from Vanuatu indicates a cooling of similar magnitude for $12 \mathrm{ka}$, suggesting the LGM cooling was at least as large [Beck et al., 1992]. Over land, Stute et al. [1995] have estimated a $5^{\circ} \mathrm{C}$ lowland cooling in Brazil by analyzing the noble gases dissolved in fossil groundwater of glacial age. While the evidence cited above also provides inadequate spatial coverage, most of these temperature estimates are indicative of low-latitude glacial cooling considerably larger than the CLIMAP reconstruction would suggest. On the other hand, analysis of alkenones in deep-sea sediments indicates changes in 
temperature of $<2^{\circ} \mathrm{C}$ in the equatorial Atlantic [Sikes and Keigwin, 1994], in the east central equatorial Pacific [Prahl et al., 1989], and in the Caroline Islands [Ohkouchi et al., 1994] and a glacial-interglacial temperature change of about $3.5^{\circ} \mathrm{C}$ in the eastern equatorial and subtropical South Atlantic [Schneider et al., 1995]. These estimates tend to support the CLIMAP SST reconstructions, as do estimates of glacial SST from $\delta^{18} \mathrm{O}$ in foraminifera [Thunell et al., 1994].

Given that the evidence cited above adds considerable uncertainty to the issue of low-latitude LGM temperatures and invites closer examination of the CLIMAP SST estimates, it is useful to revisit the geographical variations in the model-CLIMAP agreement. At low latitudes $\left(30^{\circ} \mathrm{N}-\right.$ $30^{\circ} \mathrm{S}$ ), the correspondence between the simulated and CLIMAP zonal mean anomalies (Figures 3a-3c) is excellent in the Atlantic, mediocre in the Indian, and poor in the Pacific. These variations in the magnitude of disagreement between the glacial SST anomalies simulated by the climate model and those reconstructed by CLIMAP roughly parallel the geographical variations in the precision of the transfer functions used by CLIMAP to estimate SST. Prell [1985] tested these transfer functions and calculated the standard errors for each ocean basin. They ranged from $1.2^{\circ} \mathrm{C}$ for the Atlantic transfer function used on Atlantic data to just over $3^{\circ} \mathrm{C}$ for the Pacific transfer function used on Pacific data. Even larger errors $\left(\sim 4^{\circ} \mathrm{C}\right)$ occurred when the Pacific transfer function was tested using Indian Ocean core tops. This suggests that the Pacific, where the model-CLIMAP disagreement is most pronounced, is a particularly difficult place to reconstruct SST using carbonate microfossils.

Several issues could hinder SST estimation using planktonic microfossils in the low-latitude Pacific. Probably the most important of these involves glacial-interglacial variations in carbonate dissolution. In the more corrosive deep waters of the Pacific, dissolution can adversely affect the preservation of calcareous fauna, and Moore et al. [1980] have noted that it increases the proportion of cool-dwelling species in sediments. Because of greater carbonate dissolution in the modern Pacific than during glacial times, an underestimation of glacial-interglacial temperature differences can be introduced if the modern calibration of the statistical transfer functions uses planktonic abundances from core tops that have disproportionately reduced numbers of warm-dwelling species. Under these circumstances the performance of the transfer functions for modern samples would not be indicative of their ability to estimate glacialinterglacial SST changes, since in the latter case this hypothetical underestimation would be superimposed on the calibration uncertainties discussed previously. Miao et al. [1994] have demonstrated the potential for underestimating glacial-interglacial SST differences using a limited data set, but the possibility of a more widespread underestimation bias remains unproven.

Also, where diatoms and radiolaria yielded substantially different temperature estimates, CLIMAP assumed that the warmer diatom estimates were more accurate, and in similar cases where no diatom estimates were available, the radiolarian estimates were adjusted upward by $4^{\circ} \mathrm{C}$ [Moore et al., 1980]. While almost all of the cores adjusted in this way are between $35^{\circ}$ and $40^{\circ} \mathrm{N}$, this could also contribute to a warm bias in glacial temperatures at the poleward margin of the North Pacific subtropical gyre. Another potential complication is illustrated in the work of Ravelo et al. [1990], who demonstrate that the predominant faunal assemblages in the equatorial Atlantic do not respond primarily to SST, but rather to thermocline and seasonality changes.

Determining whether or not factors such as these can lead to erroneous paleoclimatic interpretations is a difficult task and beyond the scope of this paper. However, issues such as this can contribute to the uncertainties associated with paleoclimatic interpretations of geological data, so care must be taken to consider these uncertainties when evaluating the performance of climate models based on paleoclimatic information. Our analysis of this particular climate model simulation suggests that it is not yet possible to determine if the climate model exaggerates or underestimates low-latitude climate sensitivity based on the CLIMAP paleotemperature estimates, since the largest modelCLIMAP discrepancies occur where the uncertainties in estimation are large (i.e., the low-latitude Pacific).

\subsection{Implications for Design of Paleoclimatic Data Sets}

The subjectively analyzed, gridded CLIMAP glacial SST anomalies can serve as an excellent case study for differentiating two different sources of uncertainty in global paleoclimatic data sets of its kind, where derived estimates of a climatic quantity are presented. Because it has been widely used by climate modelers, both for model evaluation and (more commonly) as an SST boundary condition, any insights gained may have broader value as well. One source of uncertainty is associated with the climatic interpretation of a particular paleoclimatic observation, which in the case of the CLIMAP data set is the information recorded in a particular sediment core. Paleoclimatic reconstruction involves the development and quantification of a model that allows past values of climatic quantities to be inferred from physical, chemical, or biological evidence found in the geological record. Thus in addition to errors due to sampling and chronology, some error will also result from the inadequacies of the model. The possibility that this type of error could affect CLIMAP SST estimates at low latitudes was addressed in the previous subsection.

A second and potentially more insidious source of error is associated with determining global values from unevenly spaced observations. This error can be very serious when there are large areas with sparse data, since the procedure used to fill the gaps need not have the appropriate physical constraints. This is particularly true in the case of paleocli- 
matic data, where the goal is to reconstruct past climates that may be very different from the present. By performing comparisons between climate models and paleodata by sampling only at those discrete points where data are available, this source of error can be avoided. Thus it may be a more appropriate way to evaluate model performance, and paleoclimatic data sets should be designed to facilitate comparisons of this kind.

Generating data sets for use as model input (e.g., for climate models, vegetation models, etc.) often requires complete spatial coverage, so errors associated with filling gaps in data coverage may be unavoidable. For this purpose, objective analysis techniques may be preferable to subjective contouring, not because they guarantee smaller error but rather because they allow one to determine the influence of an observation (or set of observations) on the analysis. This leads to a more flexible product that accommodates updates more readily as new information or revised interpretations become available.

Finally, there is a need for a more integrated approach to the development of paleoclimatic databases, in which information from different paleoclimatic indicators is reconciled. This may be a difficult task that will require an improved understanding of the physical, chemical, and biological processes that record climate information in geological data. However the "value added" to researchers attempting to model the climate system would be considerable. Whether or not this goal can be readily accomplished, in the meantime it is imperative that users of paleoclimatic data become better informed about their origins, limitations, and uncertainties.

Acknowledgments. The authors sincerely thank S. Manabe for his strong support of this work, for frequent discussions about paleoclimate modeling, and for his comments on an earlier version of the manuscript. The idea of making separate model-CLIMAP comparisons for each ocean originated in a discussion with $\mathrm{N}$. Shackleton. We also thank T. Crowley, W. Curry, J. Mahlman, K. Miller, W. Prell, and J. R. Toggweiler, along with an anonymous reviewer, for their valuable comments and suggestions on various versions of this paper. C. Raphael deserves special thanks for her assistance in preparing the color plates. The opportunity for one of us (EPM) to perform this research was provided by the Undergraduate Summer Research Program in Atmospheric and Oceanic Sciences at Princeton University.

\section{References}

Anderson, D. M., W. L. Prell, and N. J. Barratt, Estimates of sea surface temperature in the Coral Sea at the last glacial maximum, Paleoceanography, 4, 615-627, 1989.

Beck, J. W., R. L. Edwards, E. Ito, F. W. Taylor, J. Recy, F. Rougerie, P. Joannot, and C. Henin, Sea-surface temperature from coral skeletal strontium/calcium ratios, Science, 257, 644-647, 1992.
Broccoli, A. J., and S. Manabe, The influence of continental ice, atmospheric $\mathrm{CO}_{2}$, and land albedo on the climate of the last glacial maximum, Clim. Dyn., 1, 87-89, 1987.

Broecker, W. S., and G. H. Denton, The role of ocean-atmosphere reorganizations in glacial cycles, Geochim. Cosmochim. Acta, 53, 2465-2501, 1989.

Burckle, L. H., D. Robinson, and D. Cooke, Reappraisal of sea-ice distribution in Atlantic and Pacific sectors of the Southern Ocean at 18,000 yr B.P., Nature, 299, 435-437, 1982.

Cess, R. D., et al., Interpretation of cloud-climate feedback as produced by 14 general circulation models, Science, 245, 513-516, 1989.

Climate: Long-Range Investigation, Mapping, and Prediction (CLIMAP) Project Members, Seasonal reconstructions of the Earth's surface at the last glacial maximum, Map and Chart Series MC-36, Geol. Soc. of Am., Boulder, Colo., 1981.

Guilderson, T. P., R. G. Fairbanks, and J. L. Rubenstone, Tropical temperature variations since 20,000 years ago: Modulating interhemispheric climate change, Science, 263, 663-665, 1994.

Imbrie, J., and N. G. Kipp, A new micropaleontological method for paleo-climatology: Application to a late Pleistocene Caribbean core, in The Late Cenozoic Glacial Ages, edited by K. K. Turekian, pp. 1-81, Yale Univ. Press, New Haven, Conn., 1971.

Levitus, S., Climatological atlas of the world ocean, NOAA Prof. Pap. 13, 1982.

Manabe, S., and A. J. Broccoli, A comparison of climate model sensitivity with data from the last glacial maximum, J. Atmos. Sci., 42, 2643-2651, 1985 a.

Manabe, S., and A. J. Broccoli, The influence of continental ice sheets on the climate of an ice age, J. Geophys. Res., 90, 21672190, 1985b.

Miao, Q., R. C. Thunell, and D. M. Anderson, Glacial-Holocene carbonate dissolution and sea surface temperatures in the South China and Sulu seas, Paleoceanography, 9, 269-290, 1994.

Moore, T. C., Jr., et al., The reconstruction of sea surface temperatures in the Pacific Ocean of 18,000 B. P., Mar. Micropaleontol., 5, 215-247, 1980.

Ohkouchi, N., K. Kawamura, T. Nakamura, and A. Taira, Small changes in the sea surface temperature during the last 20,000 years: Molecular evidence from the western tropical Pacific, Geophys. Res. Lett., 21, 2207-2210, 1994.

Prahl, F. G., L. A. Muehlhausen, and M. Lyle, An organic geochemical assessment of oceanographic conditions at MANOP site C over the past 26,000 years, Paleoceanography, 4, 495-510, 1989.

Prell, W. L., The stability of low-latitude sea-surface temperatures: An evaluation of the CLIMAP reconstruction with emphasis on the positive SST anomalies, DOE Rep. TRO25, U. S. Dept. of Energy, Washington, D. C., 1985.

Ravelo, A. C., R. G. Fairbanks, and S. G. H. Philander, Reconstructing tropical Atlantic hydrography using planktonic foraminifera and an ocean model, Paleoceanography, 5, 409-431, 1990.

Rind, D., and D. M. Peteet, Terrestrial conditions at the last glacial maximum and CLIMAP sea-surface temperature estimates: Are they consistent?, Quat. Res., 24, 1-22, 1985.

Ruddiman, W. F., Climate studies in ocean cores, in Paleoclimate Analysis and Modeling, edited by A. D. Hecht, pp. 197-257, John Wiley, New York, 1985.

Schneider, R. R., P. J. Muller, and G. Ruhland, Late Quaternary surface circulation in the east equatorial South Atlantic: Evidence from alkenone sea-surface temperatures, Paleoceanography, 10, 197-219, 1995.

Sikes, E. L., and L. D. Keigwin, Equatorial Atlantic sea surface temperature for the last $30 \mathrm{kyr}$ : A comparison of $\mathrm{UK}_{37}^{\prime}, \delta^{18} \mathrm{O}$, 
anc foraminiferal assemblage temperature estimates, Paleoceanography, 9, 31-45, 1994.

Stute, M., M. Forster, H. Frischkorn, A. Serejo, J. F. Clark, P. Schlosser, W. S. Broecker, and G. Bonani, Cooling of tropical Brazil $\left(5^{\circ} \mathrm{C}\right)$ during the last glacial maximum, Science, 269 , 379-383, 1995.

Sun, D.-Z., and R. S. Lindzen, Water vapor feedback and the ice age snowline record, Ann. Geophys., 11, 204-215, 1993.

Thunell, R., D. Anderson, D. Gellar, and Q. Miao, Sea-surface temperature estimates for the tropical western Pacific during the last glaciation and their implications for the Pacific warm pool, Quat. Res., 41, 255-264, 1994.

Webster, P. J., and N. A. Streten, Late Quaternary ice age climates of tropical Australasia: Interpretations and reconstructions, Quat. Res., 10, 279-309, 1978.

A. J. Broccoli, Geophysical Fluid Dynamics Laboratory, Princeton University, P. O. Box 308, Princeton, NJ 08542. (e-mail: ajb@gfdl.gov)

E. P. Marciniak, Lincoln Laboratory, Massachusetts Institute of Technology, 244 Wood Street, Lexington, MA 02173. (e-mail: emilym@ll.mit.edu)

(Received May 8, 1995; revised October 23, 1995; accepted October 25, 1995.) 